\title{
Rural-Urban Divide: 6 Urgent Issues to Focus On
}

\author{
Prof. Ankur Singh \\ Secretary, ISTE Rajasthan Section, 84, Umrao Nagar, Ramjan Ka Hatha, Banad Road, Jodhpur - 342015 \\ (Raj.) e-mail Address: Mobile No. 09461268708
}

\begin{abstract}
Worldwide, inequality of individual wealth and health is extreme, especially between rural and urban world. At the start of 2014, the richest 85 people on the planet owned as much as the poorest half of the humanity. Between March 2013 and March 2014, these 85 people grew \$ 668 million richer each day. On the other extreme, rural billions are living in hand to mouth condition, resulting in farmers' suicide. The situation is no different in India. According to a study by the Asian Development Bank, the Gini coefficient has worsened in India between 1993 and 2009-10 going up from 33 to 37. There are great disparities in income distribution in India. Top $1 \%$ population holds $48.7 \%$ resources, top $10 \%$ population holds $73.8 \%$ resources while bottom $10 \%$ population holds only $0.2 \%$ resources! Further, the cycle of malnutrition is the determining factor for India's future. The exceptionally high rates of malnutrition in India and South Asia are rooted deep in the soil of inequality between men and womenearch, field enquiries and observations reveal that many design and delivery deficiencies exist in the present rural systems and efforts, which need to be addressed on top priority basis. Rural development institutions are required to focus on such six issues for poverty alleviation, human resource development, enhanced quality of life in rural areas. The six urgent issues to focus on are :
\end{abstract}

1. Empowerment of woman and children for sustainable development, to do away with the sustainable destruction practices, as being observed every where today.

2. Equitable distribution of water, food (nutrition), health, electricity and sanitation services is required.

3. Livelihood through Green Technology \& Agriculture is today's requirement to combat climate change effects.

4. Value-addition is required as a major component in the area of deteriorating value system in rural areas also as in urban areas (More materialistic westernized attitudes).

5. Dedication and devotion to duty on the part of rural institutions is missing in the present efforts in general. Therefore, recruitment of dedicated work force to man the rural missions and institutions is urgently needed.

6. Strengthening of the efforts to provide inclusive, employment-oriented and sustainable quality education right from primary to $\mathrm{Ph} . \mathrm{D}$. level in rural areas.

The above six solutions will play a great role in reducing the ever-increasing burden on urban areas also, arising out of huge rural to urban migration in search of livelihood, education, health, empowerment.

\section{INTRODUCTION :}

$\checkmark$ Worldwide, inequality of individual wealth and health is extreme, especially between rural and urban world. At the start of 2014, Oxfam calculated that the richest 85 people on the planet owned as much as the poorest half of humanity. Between March 2013 and March 2014, these 85 people grew \$ 668 million richer each day.

$\checkmark$ The situation is no different in India. According to a study by the Asian Development Bank, the Gini coefficient (a widely-used measure of inequality; the higher the value, higher the income gap) has worsened in India between 1993 and 2009-10 going up from 33 to 37.

$\checkmark \quad$ There are great disparities in income distribution in our country. Top $1 \%$ population holds $48.7 \%$ resources, top $10 \%$ population holds $73.8 \%$ resources while bottom $10 \%$ population holds only $0.2 \%$ resources !

$\checkmark$ The cycle of malnutrition is the determining factor for India's future. The exceptionally high rates of malnutrition in India and South Asia are rooted deep in the soil of inequality between men and women. The vicious cycle of malnutrition among the women of rural India perpetuates the equally vicious cycle of persistent hunger and poverty for all rural Indians.

$\checkmark \quad$ With Indian agriculture growing slowly, employment in agriculture too has been increasing at a low rate. Urban employment has not expanded rapidly enough to provide work for the growing rural population. So, is the rise in non-agricultural employment in recent years driven more by distress than demand. 

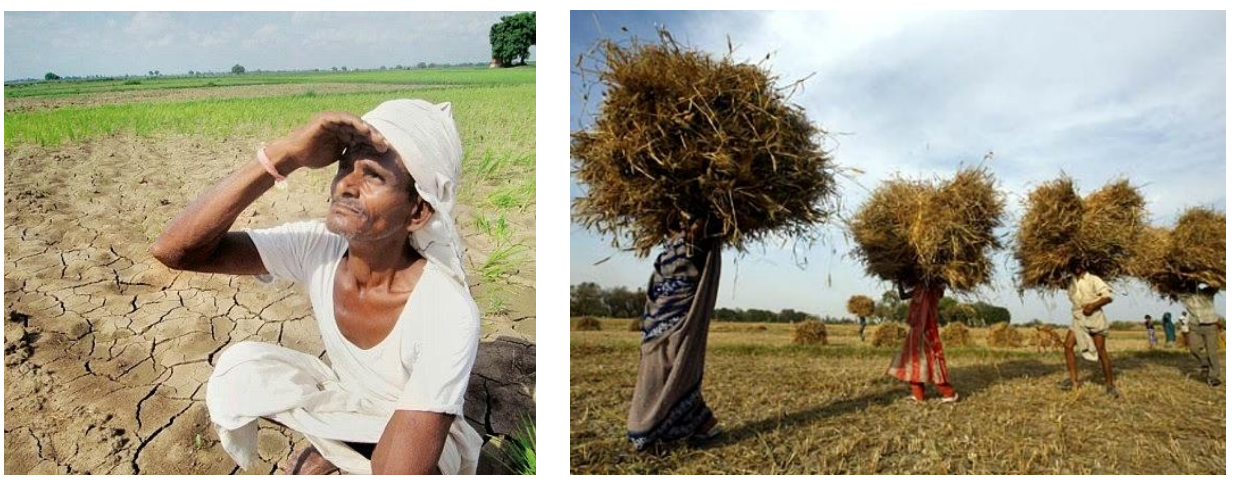

$\checkmark$ India's wealth is rising and so is inequality. Gaps are widening not just between rural and urban areas but also within these areas.

$\checkmark$ Data on household consumption expenditure, collected by National Sample survey Office under the Ministry of Programme Implementation, could be used as a proxy to analyse income inequality. The table below shows the difference between rural and urban income from 2004-'05 to 2011-'12.

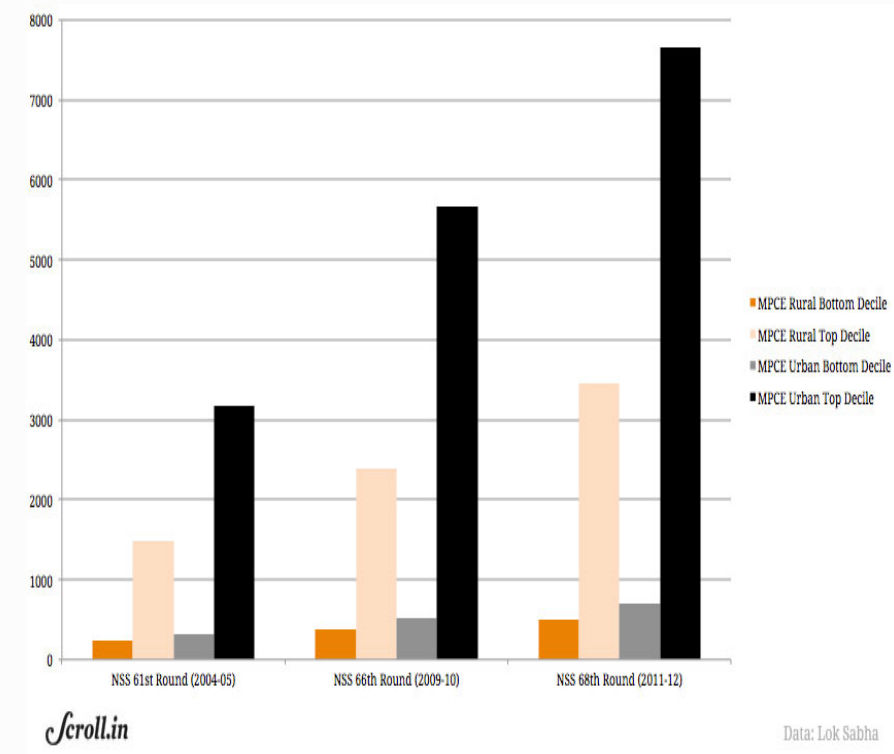

Income in Urban and Rural Areas, Top and Bottom Deciles (Rs.)

India is becoming more unequal, not just between rural and urban areas but also within rural and urban areas. The income for the bottom decile (bottom 10\% of the population) has increased from Rs 227.8 in 2004-'05 to Rs 503.5 in 2011-'12.

$\checkmark$ During the same period, the income of the top decile (top 10\% of the population) increased from Rs 1,478 to Rs 3,460 .

$\checkmark$ The story is similar in urban areas. Social protection is a cushion for those at the bottom against the effects of inequality. Social protection policies play an important role in reducing poverty and inequality and supporting inclusive growth by boosting human capital and productivity, supporting domestic demand and helping transform national economies.

$\checkmark$ According to a report by the International Labour Organisation, only 27\% of the global population enjoys access to comprehensive social security systems whereas $73 \%$ are covered only partially or not at all. India does badly on this count.

$\checkmark$ The global average on social spending is $8.8 \%$ of GDP. Among BRICS nations, India spends the lowest proportion of public expenditure on social protection at $2.5 \%$, while the highest is Brazil with $21.2 \%$, as of 2010. China, more populous than India, spends $6.5 \%$ of total expenditure on social-protection schemes. 


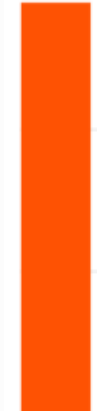

Brazil Scroll.in

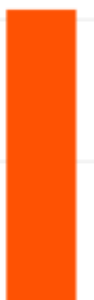

Russia

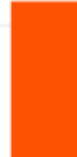

S. Africa Global average
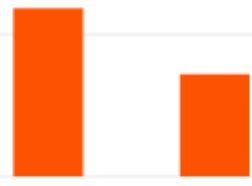

China
15

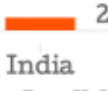

$\checkmark \quad$ Water is a prime natural resource for humans and hence a precious national asset. Nowadays, it is hard to find freshwater due to huge growth in population, agricultural and industrial activities and contamination of water resources.

$\checkmark \quad 97 \%$ of the water on the Earth is salt water, with an average salinity of 35\% (or 3.5\%, roughly equivalent to 35 grams of salts in $1 \mathrm{~kg}$ of seawater. only $3 \%$ is fresh water, of which slightly over two thirds is frozen in glaciers and polar ice caps.

$\checkmark$ The remaining unfrozen freshwater is mainly found as groundwater, with only a small fraction present above ground or in the air. Surface water is only $0.3 \%$. The planet's little fresh water is very unevenly distributed.

$\checkmark \quad$ There may be an overall shortage of water but the gravity of the problem is primarily due to improper distribution, vast differential in consumption and wastages.

$\checkmark$ Approach to management of droughts and floods has to be co-ordinated and guided at the national level for real rural development.

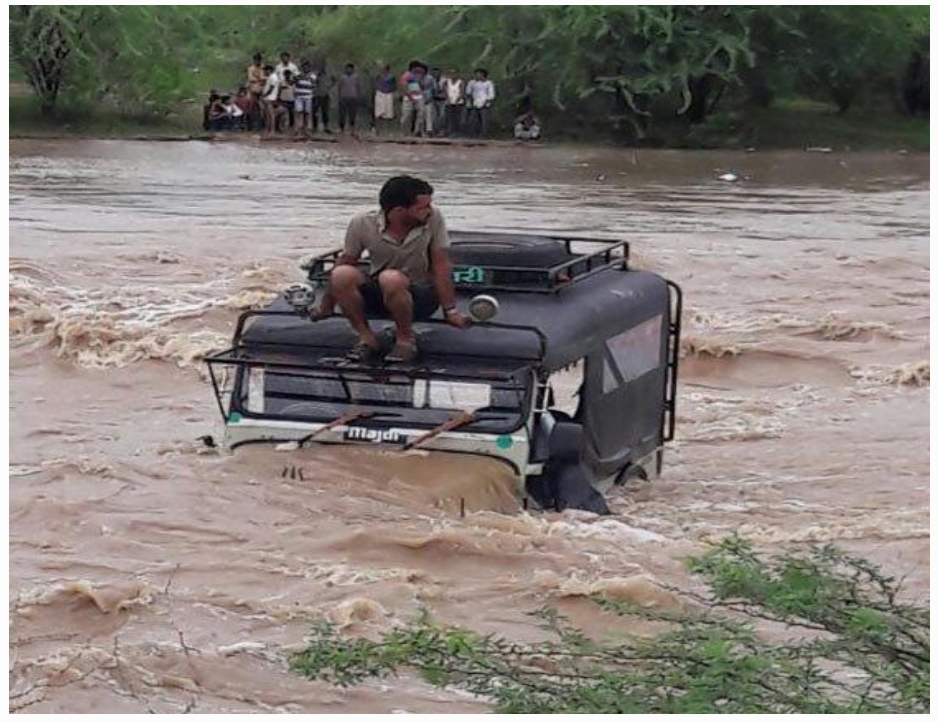

Our field enquiries and observations reveal that a few design and delivery deficiencies exist in the present system and efforts, which need to be addressed on top priority basis. Rural Institutions are required to focus on such identified issues for poverty alleviation, HRD, enhanced quality of life in rural areas. These identified, 6 urgent issues are discussed below :

\section{EMPOWERMENT OF WOMAN AND CHILDREN FOR SUSTAINABLE DEVELOPMENT}

$\checkmark$ Empowerment of woman and children for sustainable development (not for sustainable destruction, as being observed every where) is the need of the hour.

$\checkmark$ Education is the most important thing in a child's life. Children are the future for our nation and without proper education, the nation will fail. Children should be taught to value their education and parents to should instill that in their kids. That will empower them to face the challenges in life. 


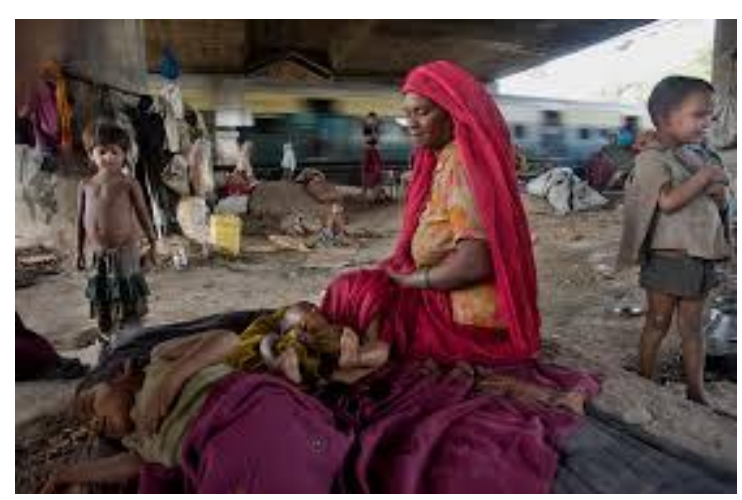

$\checkmark \quad$ India has the second worst rate of child malnutrition in the world, just behind Bangladesh. Low birth weight and child malnutrition are the primary determinants of ill-health and diminished capacity throughout life.

$\checkmark$ When children are born malnourished and underweight, they are at severe risk in all areas of personal development, health and mental capacity. They are physically weak and lack resistance to disease. They face a lifetime of disabilities, a lowered capacity for learning and diminished productivity.

$\checkmark \quad$ The cost to India of this deficiency, solely in economic terms, has been estimated to be as much as US\$28 billion per year in reduced GDP. This is greater than India's total annual public expenditures on nutrition and health combined.

$\checkmark$ This reality is a clear and direct result of the subjugation, marginalization and disempowerment of women throughout their lives.

$\checkmark \quad$ We should not need to focus exclusively on women as mothers in order to be committed to transforming their status. Yet, in their role as mothers, they do represent the most critical link in the chain of human wellbeing and development.

$\checkmark \quad$ It is widely recognised that the health and nutritional status of a pregnant woman dramatically affects the health of her baby. A more accurate scientific understanding, however, reveals that this is only part of the story. The truth is that a woman's health, from the time she is in her own mother's womb, is the single most important factor in determining the health of her child.

$\checkmark \quad$ It is clear that traditional responses to child malnutrition, such as simply providing nutritional supplements to pregnant women, are both inadequate and ultimately futile. If India is to interrupt the cycle of persistent hunger, the lifetime health and nutritional status of women must improve dramatically.

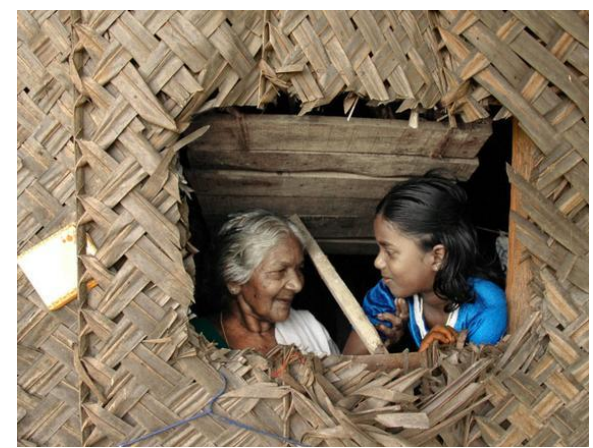

$\checkmark$ This, in turn, means transforming the way women are treated in the family and society as a whole; no longer can she eat last and least, taking whatever is left over after feeding the husband and sons.

$\checkmark \quad$ No longer can a girl-child be kept from the breast so that her mother may become pregnant sooner, to bear a son. No longer can teenage girls facing the stresses of puberty also expect to face deprivation, pregnancy and abuse.

$\checkmark \quad$ No rural project can be fully successful without active involvement of woman.

\section{EQUITABLE DISTRIBUTION OF WATER, FOOD (NUTRITION), HEALTH, ELECTRICITY AND}

\section{sanitation services :}

$\checkmark$ Equitable distribution of water, food (nutrition), health, electricity and sanitation services is urgently required. The Asian Development Bank traditionally has invested in infrastructure projects, roads, railways 
and dams but now wants to shift its focus to education and health to deal with the threat posed to social cohesion by rising inequality.

$\checkmark$ Although economic growth is necessary to reduce poverty, there is the realisation that attention has to be paid to inclusive growth. This will mean a big strategic shift at the bank. Inequality and inclusive growth should be of great concern to policy-makers and development officials.

$\checkmark$ Based on figures in its 2011 annual report, the ADB lent \$540m for education and \$20m for the health sector. That sounds like large amounts but those sectors accounted for only 4\% of total loans for 2011. Infrastructure - energy, transport, information and communications technology and water supply accounted for $69 \%$ of the bank's total loans.

$\checkmark$ From 1967 to 2011 , the percentages were $4 \%$ for education, $2 \%$ for health, $21 \%$ for energy, $25 \%$ for transport and ICT, and $8 \%$ for water supply and other municipal infrastructure and services. The total for the infrastructure sector over the period was $54 \%$. We will have to invest in health and education to make sure people are skilled enough and well enough to benefit from growth.

$\checkmark$ The ADB is working on social protection systems - health insurance, employment. India and China in recent years are placing increasing importance on social protection.

$\checkmark \quad$ In 2005, India launched the Mahatma Gandhi National Rural Employment Guarantee. The act promised 100 days of employment annually to adult members of rural households. This year India introduced an ambitious cash transfer scheme, depositing government pension and scholarship payments directly into the bank accounts of about 245,000 people, cutting out state and local officials so they have no opportunity to divert the money into their own pockets. Hundreds of thousands more people will be added to the programme in the coming months.

$\checkmark$ Floods and droughts affect vast areas of the country, transcending State boundaries. One-sixth area of the country is drought-prone covering mainly States like Rajasthan, Haryana, Karnataka, Maharashtra, Gujarat, Western Andhra Pradesh.

$\checkmark$ Out of 40 million hectares of the flood prone area in the country including States like Bihar, Bengal, Assam, Uttar Pradesh, Coastal Andhra Pradesh, Orissa, on an average, floods affect an area of around 7.5 million hectares per year.

$\checkmark$ We need to transfer the excess water to deficit areas to solve the twin problem of drought and flood side-byside. Water is the most basic, essential element in right quantity and of right quality for food (nutrition), health, electricity and sanitation services.

$\checkmark$ Big corporate houses should take a bigger social responsibility in development of health, electricity and sanitation service system in rural areas as their corporate social responsibility.

$\checkmark$ Problems related to the disposal of waste water and need of rehabilitation of village ponds in many states is a burning problem. A pond exists in a village, where all the waste water of the village gets accumulated without any treatment, thereby posing health problems to all persons, animals.

$\checkmark$ Low cost wastewater treatment systems should be constructed in the villages to treat waste water (grey water). Technology for the treatment of waste water should be simple.

$\checkmark$ Waste water from kitchen sink, wash basin, bathroom be collected and used for flushing, cleaning, gardening. Restore and use old water tanks.

$\checkmark$ Conserve wetlands, they provide a range of ecological services e.g. water conservation, ground water recharge, preservation of flora and stop encroachment on oran land, forests and wetlands fauna.

$\checkmark$ Capture rain water. If rain water from only $2 \%$ area of country is captured, it is equivalent to 117 litres / person!

$\checkmark$ Adopt traditional rain-water collecting Taankaa Technique of Rajasthan and roof top rain water harvesting techniques for sustainable development.

$\checkmark$ Water Conservation and environment protection only will ensure human-life insurance on this planet. Therefore, create mass awareness among the rural public.

$\checkmark$ Remember Our Fundamental Duty : Article 51- A (g) of the constitution of India enjoins upon every citizen of India " to protect and improve the natural environment including forests, lakes, rivers and wildlife and to have compassion for living creatures".

\section{TODAY'S REQUIREMENT - LIVELIHOOD THROUGH GREEN TECHNOLOGY :}

$\checkmark \quad$ More quality schools, ITIs, colleges and universities should be opened in rural areas by the Govt. with focus on Green Lifestyles, Green Technology.

$\checkmark$ Promote green, vocational training programmes and initiatives for self-reliance.

$\checkmark \quad$ Skill Development programmes may be commenced on Clean Technologies like Solar Technologies, Wind Power Technologies. 
$\checkmark$ MoRD should integrate environment in its programmes, to improve the ecological balance for healthier, cleaner environment.

$\checkmark$ The Watershed development programmes should be taken up on priority with focus primarily on ecological restoration strengthening related livelihoods.

$\checkmark$ Programme reducing soil erosion, increasing water storage ( in-situ moisture conservation, surface water bodies, groundwater recharge), improving vegetative cover, particularly in fallow land should be taken up.

$\checkmark$ Rural Roads are vital for economic growth, poverty alleviation, provision of all the above services in the villages.

\section{VALUE-ADDITION IN THE FORM OF VALUE SYSTEM :}

$\checkmark \quad$ Value-addition is required as a major component in the era of deteriorating value system in rural areas.

$\checkmark$ Our prime objective should be to strengthen rural India in a holistic manner, as NCRI is trying to do.

$\checkmark \quad$ Indian value system (sanskaars) should be part of all social, educational projects in rural areas. It will ensure the lasting success of the projects.

$\checkmark$ Today, everyone always takes education to make more money but it's more than money. The sanskaars should be integral part of education system. Sanskaars + Education will turn our youth power into invaluable demographic dividend!

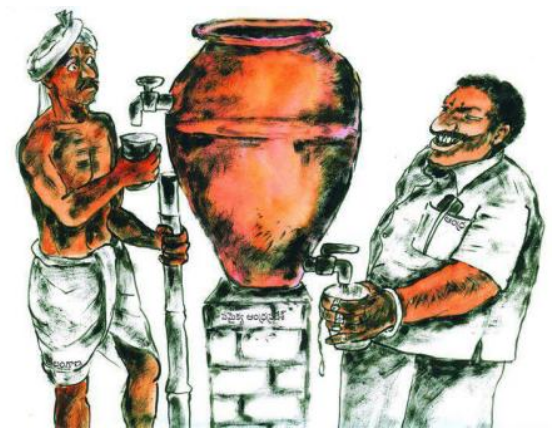

$\checkmark \quad$ Eco-Friendly Habits \& Lifestyles should be promoted.

\section{a. Dedication and Devotion to Duty, Keystone of Rural Success :}

$\checkmark$ Dedication and devotion to duty is the keystone of success of rural projects. If this is achieved, more half battle will be immediately won.

$\checkmark$ Dedication and devotion to duty is missing in the present efforts in general. Therefore, recruitment of dedicated work force to man the rural missions is needed.

$\checkmark$ We should inculcate the spirit of dedication and devotion to duty in the work-force manning the rural projects.

$\checkmark$ The rural projects should be taken as national missions of nation development through upliftment of our rural masses.

$\checkmark$ Sab Ka Sath Sab Ka Vikas should be the guiding philosophy and strategy of India, as enunciated by our Honourable Prime Minister Sri Narendra Bhai Modi.

$\checkmark$ Always remember the famous Geeta Gyan : Karma hee dharma hai. Rural project personnel should be oriented to become the real karma yogi.

\section{INCLUSIVE, EMPLOYMENT-ORIENTED AND SUSTAINABLE QUALITY EDUCATION :}

$\checkmark$ We must strengthen the efforts to provide inclusive, employment-oriented and sustainable quality education right from primary to $\mathrm{Ph} . \mathrm{D}$. level.

$\checkmark \quad$ More quality schools, colleges and universities should be opened in rural areas by the Government.

$\checkmark \quad$ Incentives should be given to private investors who open quality schools, colleges and universities in rural areas.

$\checkmark \quad$ Indian value system should be part of education curriculum in rural areas as well as in urban areas. 
Big corporate houses should take a bigger social responsibility in development of education system in rural areas as their corporate social responsibility.

$\checkmark$ More transparency is required in implementation of rural projects.

$\checkmark \quad$ Trades like Solar Technology, Wind Technology, Mobile repair, Electrician, Garment Making \& Embroidery, Zardozi \& Aari Works, Tie \& dye etc. courses should be organized.

\section{REFERENCES :}

[1] UNICEF, "The Asian Enigma", The Progress of Nations, 1996.The Hindu, June 25, 2012, MacroScan C.P.Chandra Sekhar, Jayanti Ghosh

[2] Democratic dividend can bridge the rural urban divide: Rohan Shridhar, Oct.27, 2014http://rural.nic.in/greenruraldevelopment/home.asp, http://drd.nic.in/

[3] http://www.thp.org/sai00/india/malnutrition.htm Rural poverty and agricultural performance in India:Montek S. Ahluwaliaa

[4] Prachi Salve, IndiaSpend.com · Jan 10, 2015 The Review of Rural Affairs - June 29, 2013
IWMI
MGNREGA
Assets
and
Rural
Water
Security

2011http://www.wunrn.com/news/2008/06_08/06_16_08/061608_india3.htm

[6] 11. Rural Institutions : Urgent Issues to Focus On : Acharya (Er.) Daria Singh, Ankur Singh,

[7] Ar. Ashu Dehadani, NCRI, Oct.15

[8] 12. Managing Water Management Research: Analysis of 4 decades of Research and Outreach

[9] Programmes in India, Vol - L No. 26-27, June 27, 2015 | K Palanisami, D Suresh Kumar, R PS Malik, S. Raman, G Kar, and Kadiri Mohan

[10] Water Harvesting Practices in Rajasthan \& Their Socio-Cultural, Environmental Importance : Ar. Ashu Dehadani, Masters in Sustainable Architecture, Jodhpur. 